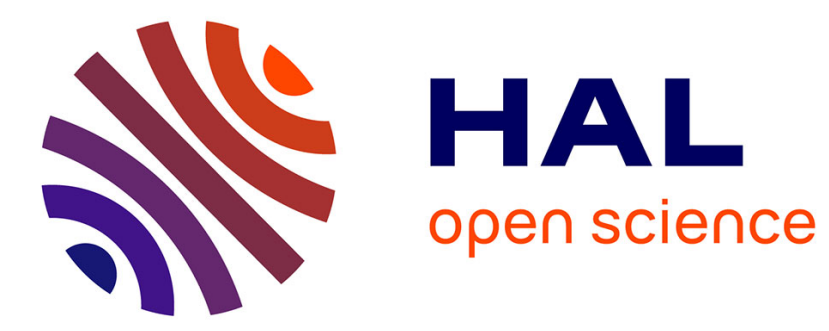

\title{
Crack effects on gas and water permeability of concretes
} Vincent Picandet, Abdelhafid Khelidj, Hervé Bellegou

\section{To cite this version:}

Vincent Picandet, Abdelhafid Khelidj, Hervé Bellegou. Crack effects on gas and water permeability of concretes. Cement and Concrete Research, 2009, 39 (6), pp.537-547. 10.1016/j.cemconres.2009.03.009 . hal-00494399

\section{HAL Id: hal-00494399 \\ https://hal.science/hal-00494399}

Submitted on 8 Nov 2018

HAL is a multi-disciplinary open access archive for the deposit and dissemination of scientific research documents, whether they are published or not. The documents may come from teaching and research institutions in France or abroad, or from public or private research centers.
L'archive ouverte pluridisciplinaire HAL, est destinée au dépôt et à la diffusion de documents scientifiques de niveau recherche, publiés ou non, émanant des établissements d'enseignement et de recherche français ou étrangers, des laboratoires publics ou privés. 


\title{
Crack effects on gas and water permeability of concretes
}

\author{
Vincent Picandet ${ }^{\mathrm{a}}$, Abdelhafid Khelidj ${ }^{\mathrm{b}}$, Hervé Bellegou ${ }^{\mathrm{a}}$ \\ ${ }^{a}$ Laboratoire d'Ingéniérie des MATériaux de Bretagne, (LIMATB), Université de Bretagne Sud, Centre de Recherche de Saint-Maudé, BP 92116,56321 Lorient, \\ Cedex, France \\ bInstitut de Rechercheen Génie Civil et Mécanique (GeM), I.U.T., Département Génie Civil, BP 420, 44606 Saint-Nazaire, France
}

\begin{abstract}
The relationship between load-induced cracking and concrete permeability is studied. Ordinary concrete (OC) and high-performance concrete (HPC), including steel fiber-reinforced concrete (HPFRC), are used. Two discs, $50 \mathrm{~mm}$-thick slices, cut from 110-220 mm cylindrical specimens are diametrically loaded, as for a normal splitting test. The lateral displacement, also called the crack opening displacement (COD) is monitored for each loading cycle. After unloading, gas and finally water permeability tests are both performed, using constant head permeameter, to compare the influence of the percolating fluid and the COD. Due to the wide range of measured gas flow, Klinkenberg's and Dupuit-Forcheimer's laws are applied to compute the intrinsic gas permeability. Results suggest it increases proportionally to the cube of the COD and it matches water permeability, if only the first water percolating time is considered. The roughness parameter of the cracks induced in each concrete, is compared and discussed.
\end{abstract}

\section{Introduction}

The permeability of concrete plays a critical role in controlling the properties of concrete, and the serviceability of reinforced concrete. Besides the permeability and general stability, the ability of cracks to conduct gases and water is of significant importance for structures subjected to water and/or vapor pressure (i.e. basements, waterretaining structures, water reservoirs, waste containers and confining enclosures of nuclear power plants).

The evolution of concrete permeability could be regarded on the one hand, as a function of diffuse microcracking, related to low level damage (from 0 to $15 \%$ ) before the peak load and, on the other hand, as a function of the macro-crack characteristics created beyond the peak load [1]. For low level damage, the relationships between permeability and diffuse damages have been studied experimentally after unloading [2] or under loading [1,3], and theoretically investigated [4]. At the load peak, interconnected micro cracks initialize crack formation. When a macro crack has formed, a marked increase of permeability takes place, and the permeability essentially depends on the width, the tortuosity and connectivity of the newly created channels $[5,6]$.

Generally, tensile cracks, due to shrinkage and/or load are almost unavoidable in reinforced concrete structures. However, due to difficulties in generating desirable crack patterns in concrete specimens and the availability of appropriate methods for concrete permeability measurements, a limited number of studies have been done on both gas and water

\footnotetext{
* Corresponding author. Tel.: +332978745 76; fax: +33297874572. E-mail addresses: vincent.picandet@univ-ubs.fr (V. Picandet), abdelhafid.khelidj@univ-nantes.fr (A. Khelidj), herve.bellegou@univ-ubs.fr (H. Bellegou)
}

permeability of cracked concrete. Most researchers focus on the water permeability of concrete. It can be regarded as representative of common in-service percolations. However the permeability values significantly decrease with time due to water-cement matrix interactions, i.e. dissolution/precipitation of hydrates and migration of fine elements, resulting in the autogeneous healing of cracks [7-9], while tests using chemically unreactive liquids such as ethanol [10] or glycol [11] show that permeability values remain constant. Moreover, it is difficult to assess accurately the effect of mechanical cracking on global transport properties, since tensile cracking may occur as a result of the exposure of previously unhydrated components to percolating water [8]. Smaller crack apertures [9] and higher temperatures [12] lead to a faster selfhealing process. This phenomenon seems more pronounced for HPC with a low water-to-cement ratio [11] and has been also observed even if no water percolation is generated through the material [13].

In the present study, permeability is measured using a constant head permeameter with nitrogen as the neutral percolating fluid [14]. During the final phase, the permeability of cracked specimens is also measured using water as the percolating fluid, in order to compare the results and to consider accidental water or vapor percolations through damaged structures. Controlled splitting tests are used to generate cracks produced by tensile stresses in cylindrical concrete specimens. This testing method has been used by other researchers [15-20] and has several advantages: Cracks are induced by tensile stress; The (COD) is recorded during loading and after unloading; the loaded cylindrical specimens can also be used for conventional concrete permeability tests, such as the Cembureau test method. Brazilian splitting tests have already emphasized a correlation between water permeability [15-17] or chloride diffusion [18] and the crack opening width, but only if the crack opening displacement is greater than $50 \mu \mathrm{m}$. 
Table 1

Details of test series and mix proportion.

\begin{tabular}{llll}
\hline Mix ingredients $\left(\mathrm{kg} / \mathrm{m}^{3}\right)$ & OC & HPC & HPFRC \\
\hline Coarse aggregate, $12.5-20 \mathrm{~mm}$ & 777 & - & - \\
Medium aggregate, 4-12.5 mm & 415 & 1011 & 966 \\
Sand (Boulonnais), 0-5 mm & 372 & - & - \\
Sand (Loire), 0-4 mm & 372 & 722 & 690 \\
Portland cement CPA-CEM I 52.5 & 353 & 400 & 400 \\
Silica fume & - & 40 & 40 \\
Steel fiber & - & - & 79 \\
Plasticizer & - & 6 & 10 \\
Filler & - & 72.2 & 69 \\
Total water & 172 & 140 & 140 \\
w/c ratio & 0.49 & 0.29 & 0.29 \\
\hline
\end{tabular}

A special removable device, equipped with two transducers, has been designed to monitor the COD on both sides of the discs [5]. When the predetermined COD level is reached, the discs are unloaded, and a gas permeability test is performed. The same specimen can be diametrically loaded several times, and its increase in permeability can be observed without scattering results, related to measurements performed on different discs and due to the natural heterogeneities of the material. Thus, it is possible to evaluate the influence of small lateral displacements on the gas permeability of a given disc [20], and to study accurately the transition between the diffuse fluid percolation and the localized fluid flow through the crack, i.e. the effect of micro crack interconnection on permeability. The wide range of measured gas flow requires an analysis of the results according Klinkenberg's and Dupuit-Forcheimer's laws, to take into account respectively the slip flow in undamaged specimens and the inertial flow inside the created cracks. When the transition between the two gas flow regimes occurs, the values of intrinsic gas permeability calculated from the two theories are detailed and compared.

Moreover, after each loading phase, sequential crack patterns are also observed under a video microscope so that the crack length and width can be accurately measured and correlated to results.

\section{Experimental program}

\subsection{Materials, mix proportion and specimen curing}

Three concrete mixes are made; one of ordinary concrete $(\mathrm{OC})$ with a water/cement ratio of 0.49 , and two high-performance concretes (HPC) and (HPFRC) with a water/cement ratio of 0.29 (see Table 1). In HPFRC, $4.4 \%$ of granular contained in HPC has been replaced with end-hooked steel fibers (30 mm length and $0.38 \mathrm{~mm}$ diameter) to represent $1 \%$ volume fraction of the final mix.

The concrete mixtures are cast in steel moulds and compacted using a mechanical vibrator. The vibrations were applied using a vibrating needle on OC, and using a vibrating table on HPC and HPFRC. Standard procedures (NF P 18-422) were applied in both cases to establish the time of vibration according to the measured slump. More plasticizer was used in HPFRC in order to balance the effect of fibers on workability. The vibrating period was reduced to $10 \mathrm{~s}$ for both HPC and HPRFC. It should be noted that with consolidation a slight horizontal orientation of fibers could occur. However, any preferential orientation has been noted from the examination of the slices cut into studied specimens.

Table 2

Material properties.

\begin{tabular}{lccc}
\hline & OC & HPC & HPFRC \\
\hline Modulus of elasticity (GPa) & 42 & 45 & 46 \\
Compressive strength (MPa) & 65 & 110 & 130 \\
Tensile strength (MPa) & 4.8 & 6 & 14.5 \\
Open porosity measured by water saturation (\%) & 12.1 & 9.6 & 10.4 \\
\hline
\end{tabular}

Table 3

Drying procedure.

\begin{tabular}{lllll}
\hline & OC & $\mathrm{HPC}_{(3-4)}$ & $\mathrm{HPC}_{(1-2)}$ & $\mathrm{HPFRC}$ \\
\hline Number of tested specimens & 4 & 2 & 2 & 2 \\
Conditioned room: $20 \pm 1{ }^{\circ} \mathrm{C} ; 50 \pm 5 \% \mathrm{HR}$ & 4 months & 18 months & 4 months & \\
Ventilated oven: $60 \pm 1{ }^{\circ} \mathrm{C}$ & 1 months & - & 1 month & \\
Ventilated oven: $105 \pm 2{ }^{\circ} \mathrm{C}$ & - & - & 1 month & \\
Mean water saturation degree (\%) & 13 & 35 & 3 & 4 \\
\hline
\end{tabular}

The cylindrical specimens were stored in a room maintained at $20{ }^{\circ} \mathrm{C}$ with $95 \%$ relative humidity ( $\mathrm{RH}$ ) for $24 \mathrm{~h}$ after casting, and were cured in water at $20^{\circ} \mathrm{C}$ for the next 4 weeks. They were then put in a non-ventilated drying oven and heated at $60^{\circ} \mathrm{C}$ for 2 days to finish the curing procedure. Finally, they were stored in an air-conditioned room ( $20 \pm 1{ }^{\circ} \mathrm{C}$ and $\mathrm{RH} 50 \pm 5 \%$ ) for four months prior to testing. Their mechanical characteristics and material properties at 28 days were measured, and the results are given in Table 2.

It should be noted that the significant amount, more than $350 \mathrm{~kg} / \mathrm{m}^{3}$ of cement made with over $90 \%$ clinker and with less than $5 \%$ of filler, combining with the optimal maturation conditions, produced a concrete with greater mechanical properties. These mixes have been used in parallel studies: the OC, using four granular gradations, was the concrete used in a French national program. Many experimental data are available about it [5]. The HPC and HPFRC are high-performance concretes designed to build high-strength beams subjected to alternative cyclic loading [21].

\subsection{Sample preparation and drying procedure}

Concrete cylinders were cut using a diamond blade saw to obtain $50 \mathrm{~mm}$-thick discs. Two discs were extracted from each central portion of the cylinder in order to avoid any end effect. The discs were then ground true. Their thickness was measured with an accuracy of $0.1 \mathrm{~mm}$. Their curved surface was sealed with two epoxy resin coats to ensure a one-dimensional gas flow inside the discs during permeability tests.

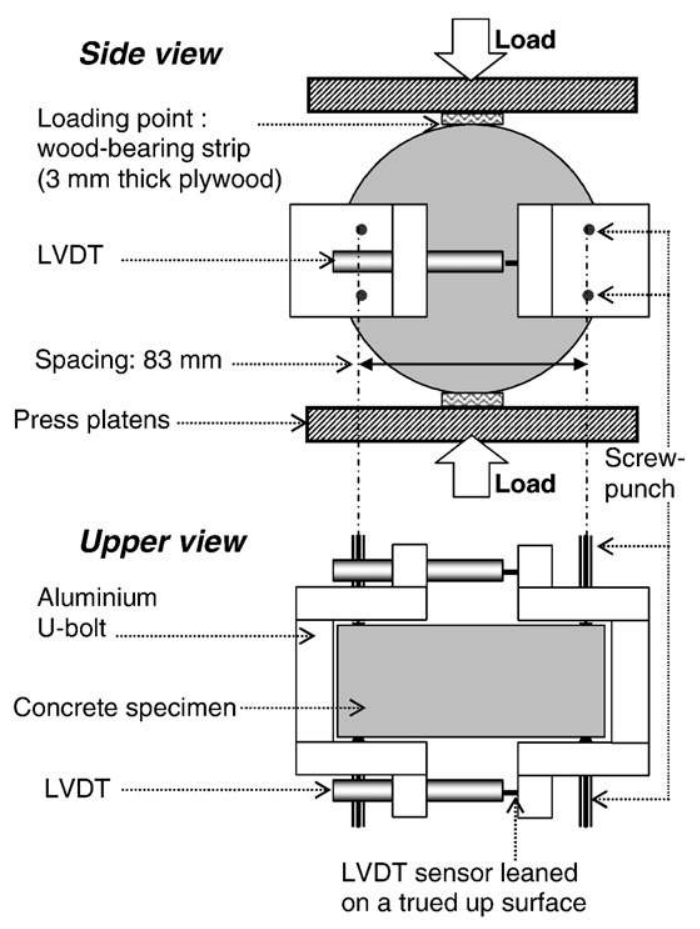

Fig. 1. Lay-out of COD measurement set-up. 


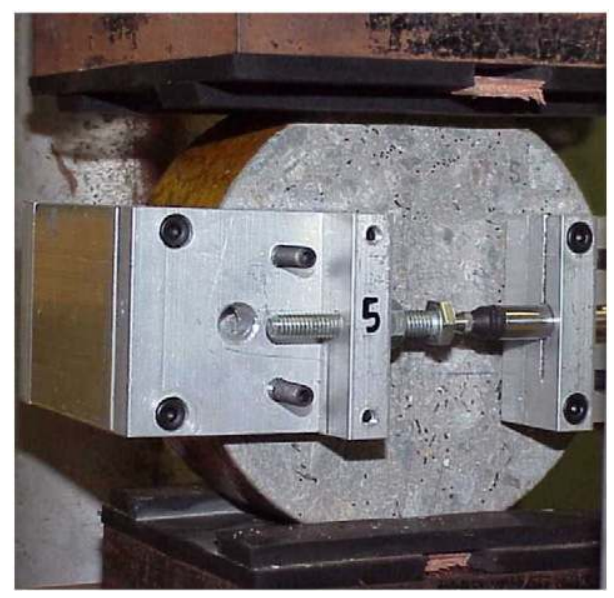

Fig. 2. COD measurement during loading.

Drying the discs is necessary before proceeding to the gas permeability test. The discs were first stored in an air-conditioned room at $20{ }^{\circ} \mathrm{C}$ and $50 \% \mathrm{HR}$, and oven-dried at $60{ }^{\circ} \mathrm{C}$ and $105{ }^{\circ} \mathrm{C}$ as shown in Table 3. Before being tested, the concrete discs were cooled for $48 \mathrm{~h}$ in a desiccator at $20^{\circ} \mathrm{C}$.

Twenty $110 \times 220-\mathrm{mm}$ cylindrical specimens were prepared from a single batch of each mix. Two samples and six discs from each batch, dried in a ventilated oven at $105^{\circ} \mathrm{C}$ until they reached constant weight (i.e. over a period of six months for HPC discs), were regarded as the dry reference while two other samples, stored in water since the day after casting, were considered as the water saturated reference and gave the water open porosity reported in Table 2 . From these data, the degrees of saturation of tested discs were deduced (see Table 3 ).

The water content of concrete has a direct influence on the gas permeability measurements $[2,22,23]$. The moisture conditioning of specimens was carefully controlled and the degree of water saturation in the discs was maintained constant during all the gas permeability tests and until the final water permeability tests.

\subsection{Pre-cracking of samples using controlled splitting tests}

Controlled splitting tests are used to induce cracks in the specimens. Diametrical loading (i.e. under Brazilian test configuration) is one of the methods used for estimating the tensile stress of concrete through indirect tension. This stress mode is applied to the discs (110 $\mathrm{mm}$ in diameter and $50 \mathrm{~mm}$ in thickness) obtained from slicing 110-220 mm concrete cylinders (Section 2.2). These discs can be directly tested in the permeameter cell after each loading cycle. The

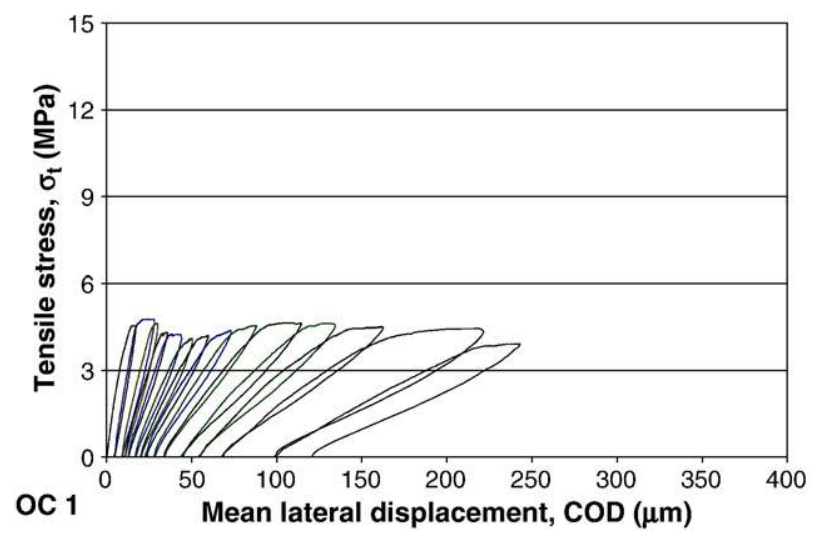

Fig. 3. Applied tensile stress versus mean crack opening displacement of OC.

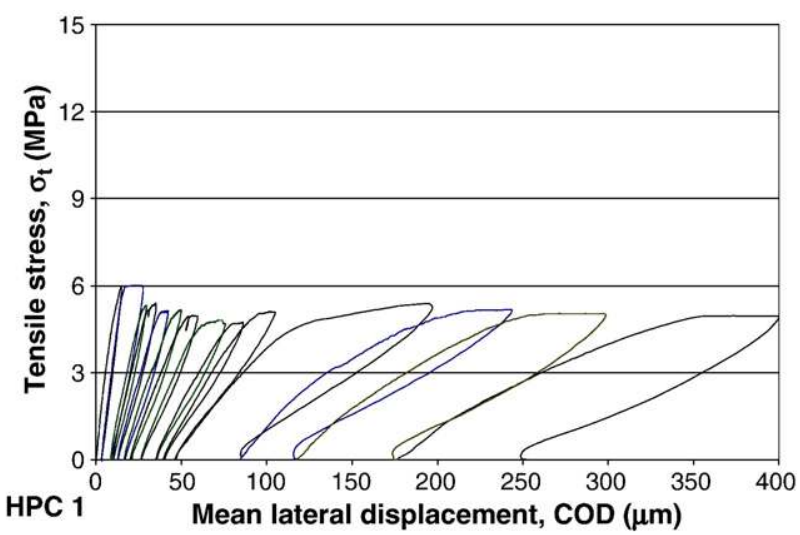

Fig. 4. Applied tensile stress versus mean crack opening displacement of HPC.

discs are diametrically loaded until a predetermined lateral displacement is obtained.

Two LVDT sensors, with a range of $0.5 \mathrm{~mm}$ and a precision of $1 \mu \mathrm{m}$, measure the diametrical displacement which is normal to the load axis along the two opposite sides of the disc. Their average is called lateral displacement or crack opening displacement (COD) [5,6,15-20]. The sensors are maintained by two U-bolts clamped to the disc via screwpunch (Figs. 1 and 2). At the end of each loading cycle, the U-bolts are removed. The axis of loading, as well as the sites of the screw-punch, is precisely located with a marker. When a disc is reloaded, the axis is preserved, as well as the site of the U-bolt. The plywood load-bearing strips are changed. The lateral displacement measurements are reinitialized with the value of the last displacement recorded on the same disc, i.e. the last COD, recorded $15 \mathrm{~min}$ after unloading, called residual displacement, $\delta_{\text {res, }}$, thereafter (Section 3.1).

Every disc undergoes 4 to 17 cycles to obtain various lateral displacements under loading. The test results shown in Figs. 3-5 were plotted by a curve of the average displacement of the two LVDTs as a function of tensile stress. The stress is defined as $\sigma_{t}=2 P / \pi L D$, where $\sigma_{t}$ is the maximum tensile stress perpendicular to the loading direction along the diameter from one load point to the other, $P$ is the force applied to the specimen, $L$ is the specimen length or thickness, and $D$ is the specimen diameter.

The load induces tensile stresses concentrated around the secant diameter with the loading plan. The damage is localized and a single crack crossing the disc is generally observed in this plan [5,6,15-20]. Actually, due to the load-bearing strip, the tensile stress inside specimens tends to reduce significantly in the areas located very close to the circumference, and to be slightly greater in the center. At the beginning of the test, cracks initiated in the center of the discs (Section 3.2) [5]. Once a transverse crack

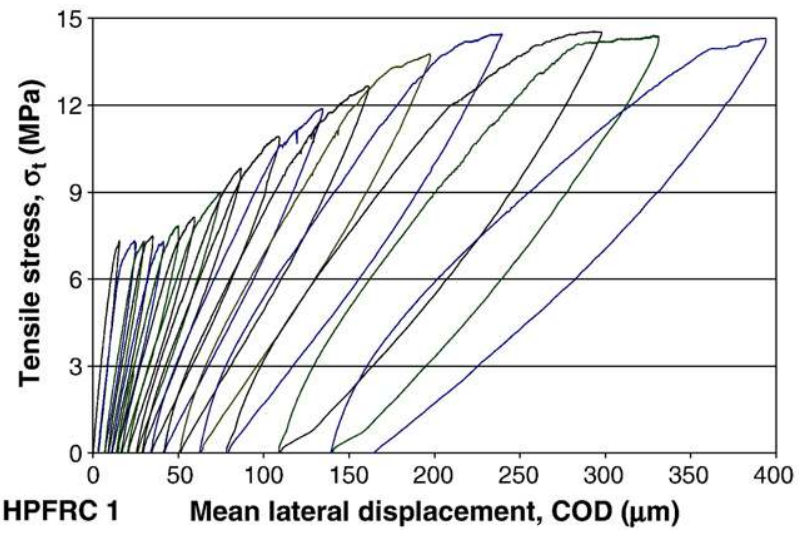

Fig. 5. Applied tensile stress versus mean crack opening displacement of HPFRC. 


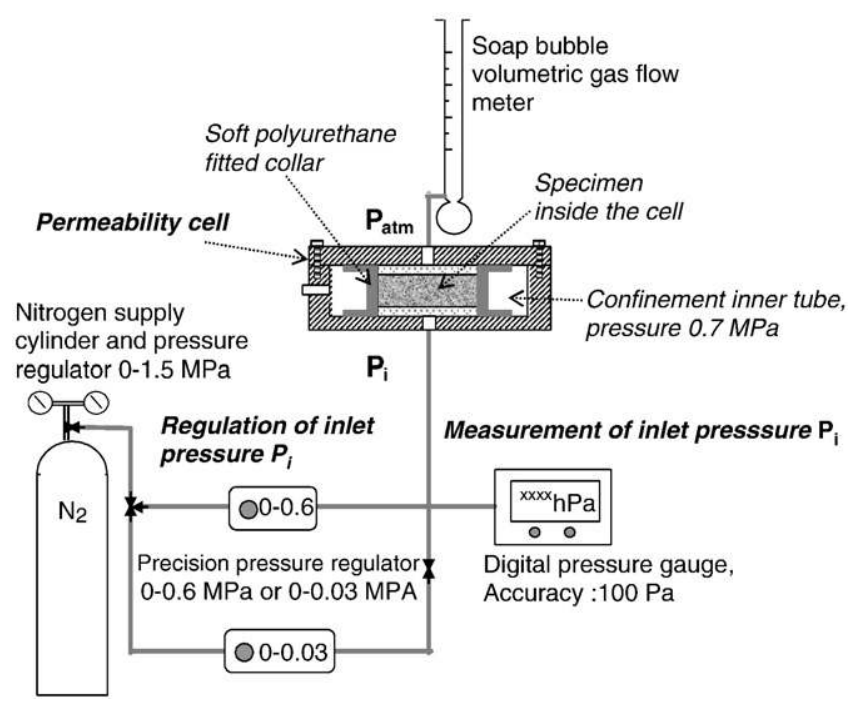

Fig. 6. Schematic layout of the gas permeability measurement set-up.

had formed, beyond the tensile peak-stress, the maximum tensile stress zone moved along the loading diameter toward its extremities as the crack grew. This testing method, unlike direct uniaxial tension, made it easier to control the post peak loading in order to induce cracks in specimens without complete damage or splitting. But the softening behavior shown in Figs. 3-5 is relative to this testing method only. The curves show particularly the effect of fibers and can be compared with the load responses obtained in the studies quoted above [5,6,15-20].

The slope of the loading and unloading phases decreased after each cycle, which indicates that the stiffness of the concrete was reduced due to the cracking of the curve during unloading.

Beyond the tensile peak-stress, when the load drops to about $80 \%$ of the peak load, it remains constant as the displacement increases, and a plateau appears in the curve (Figs. 3 and 4). At this stage, the measured displacement results primarily from the crack opening displacement. For the steel fiber-reinforced concrete, the plateau is shorter (Fig. 5). When COD increases, macro cracks occur and the stress is partially transferred to steel fibers over a larger section. The load, (i.e. the mean calculated tensile stress) continues to increase beyond the plateau until the maximum fiber strength is reached.

\subsection{Gas permeability tests}

Apparent permeability was measured using a Cembureau constant head permeameter with nitrogen as the neutral percolating gas [14]. The relative pressure $\left(P_{\mathrm{i}}-P_{\mathrm{atm}}\right)$ applied to the sample ranged between $0.05 \mathrm{MPa}$ and $0.3 \mathrm{MPa}$ for undamaged or moderate damaged specimens, and between 0.01 and $0.1 \mathrm{MPa}$ for the most cracked

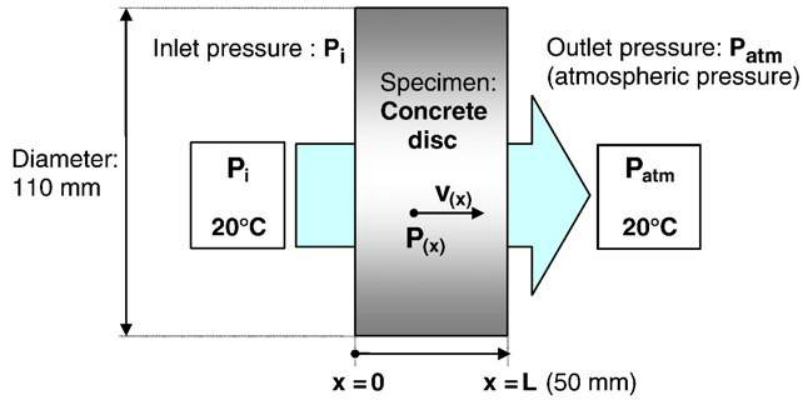

Fig. 7. Applied constant pressure gradient.

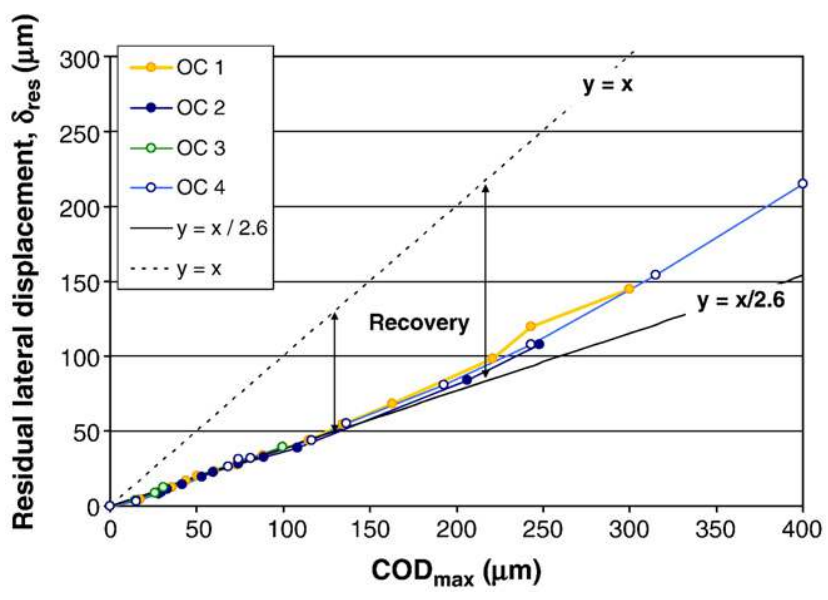

Fig. 8. COD recovery after unloading of OC.

specimens [5]. Specific pressure regulators were used according the pressure range, and the inlet gas pressure was read using a digital pressure gauge with an accuracy of $100 \mathrm{~Pa}$ (Fig. 6).

Permeability measurements were carried out in an air-conditioned room $\left(20 \pm 1{ }^{\circ} \mathrm{C}\right)$. Each gas permeability test consists of a minimum of five measurements of apparent permeability, $k_{\mathrm{A}}$, with different inlet pressures. The outlet gas percolating through the specimen was measured in atmospheric pressure using a soap bubble volumetric gas flow meter (Fig. 6). Establishing a steady state flow before actual measurements requires a significant amount of time (varying from 15 to 90 min for undamaged specimens). This condition was verified by taking two measurements at a 10-minute interval. If the two values differed by less than $2 \%$, the steady state flow condition was assumed.

For each differential pressure, the apparent coefficient of permeability $k_{\mathrm{A}}\left(\mathrm{m}^{2}\right)$ was calculated from the Hagen-Poiseuille relationship, laminar flow of a compressible viscous fluid through a porous body, using the following well-known relationship:

$k_{\mathrm{A}}=\frac{Q}{A} \frac{2 \mu L P_{\mathrm{atm}}}{\left(P_{\mathrm{i}}^{2}-P_{\mathrm{atm}}^{2}\right)}$

Where $L$ is the thickness of the sample ( $\mathrm{m}), A$ is the cross-sectional area $\left(\mathrm{m}^{2}\right), Q$ is the measured gas flow $\left(\mathrm{m}^{3} / \mathrm{s}\right), \mu$ is the coefficient of viscosity $\left(1.76 \times 10^{-5} \mathrm{~Pa} s\right.$ for nitrogen gas at $\left.20{ }^{\circ} \mathrm{C}\right), P_{\mathrm{i}}$ is the inlet pressure, (i.e. applied absolute pressure) (Pa), and $P_{\text {atm }}$ is the atmospheric pressure (Pa) (Fig. 7).

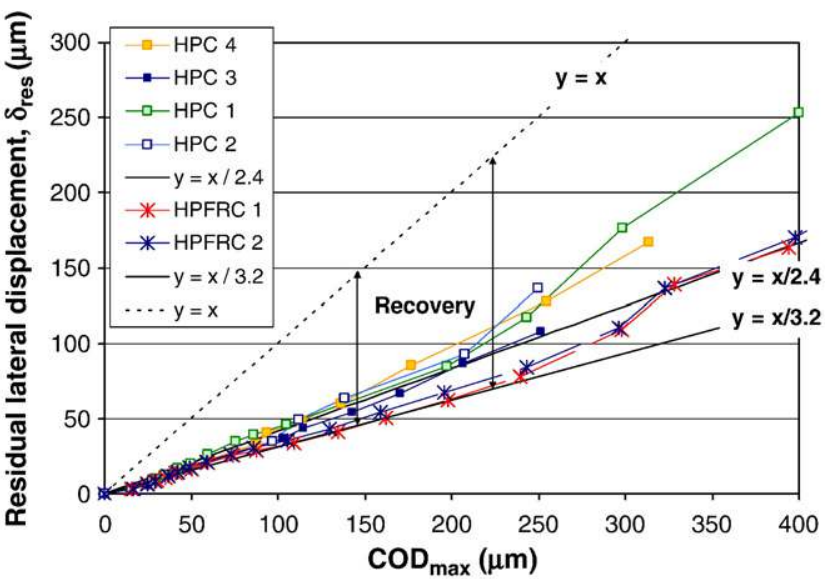

Fig. 9. COD recovery after unloading of HPC and HPFRC. 


\subsubsection{Laminar and slip flow in uncracked concrete}

The gas percolation through a fine porous body like concrete, and especially HPC, results from two flow modes: viscous flow and slip flow or Knudsen flow. Various methods exist to calculate the nonviscous flow. The most widely used is the relationship proposed by Klinkenberg [24], (Eq. (2)), which introduces the notion of an intrinsic coefficient of permeability $k_{\mathrm{V}}\left(\mathrm{m}^{2}\right)$ relative to viscous flow only.

$k_{\mathrm{A}}=k_{\mathrm{V}}\left(1+\frac{b}{P_{\mathrm{m}}}\right)$

Where $P_{\mathrm{m}}$ is the mean gas pressure, $P_{\mathrm{m}}=\left(P_{\mathrm{i}}+P_{\mathrm{atm}}\right) / 2$ and $b$ is the Klinkenberg coefficient $(\mathrm{Pa}) . k_{\mathrm{V}}$ is the limiting value of gas permeability when the mean pressure $P_{\mathrm{m}}$ approaches infinity. The determination of $k_{\mathrm{V}}$ consists in measuring $k_{\mathrm{A}}$ at different pressures $\left(P_{\mathrm{i}}\right)$ and in plotting it against the inverse of the mean pressure $\left(1 / P_{\mathrm{m}}\right)$. From the five differential pressures applied, the correlations of the linear regressions are satisfactory with a coefficient higher than 0.99 .

\subsubsection{Turbulent and inertial gas flow in cracked concrete}

Considering a macroscopic scale, the equation of a monodirectional flow (in $\mathrm{O}_{x}$ direction) is given in Dupuit-Forcheimer's law $[25,26]$ which can be written for this case in Eq. (3).

$-\frac{\mathrm{d} P}{\mathrm{~d} x}=\alpha \mu v+\beta \rho v^{2}$

Where, at the abscise $x$ (Fig. 7), $P$ is the gas pressure (Pa), $\rho$ is the fluid density $\left(\mathrm{kg} \mathrm{m}^{-3}\right), v$ is the gas velocity $\left(\mathrm{m} \mathrm{s}^{-1}\right)$ in steady state flow condition. $\alpha$ is the constant value equal to the inverse of $k_{\mathrm{V}}\left(\mathrm{m}^{-2}\right)$ and

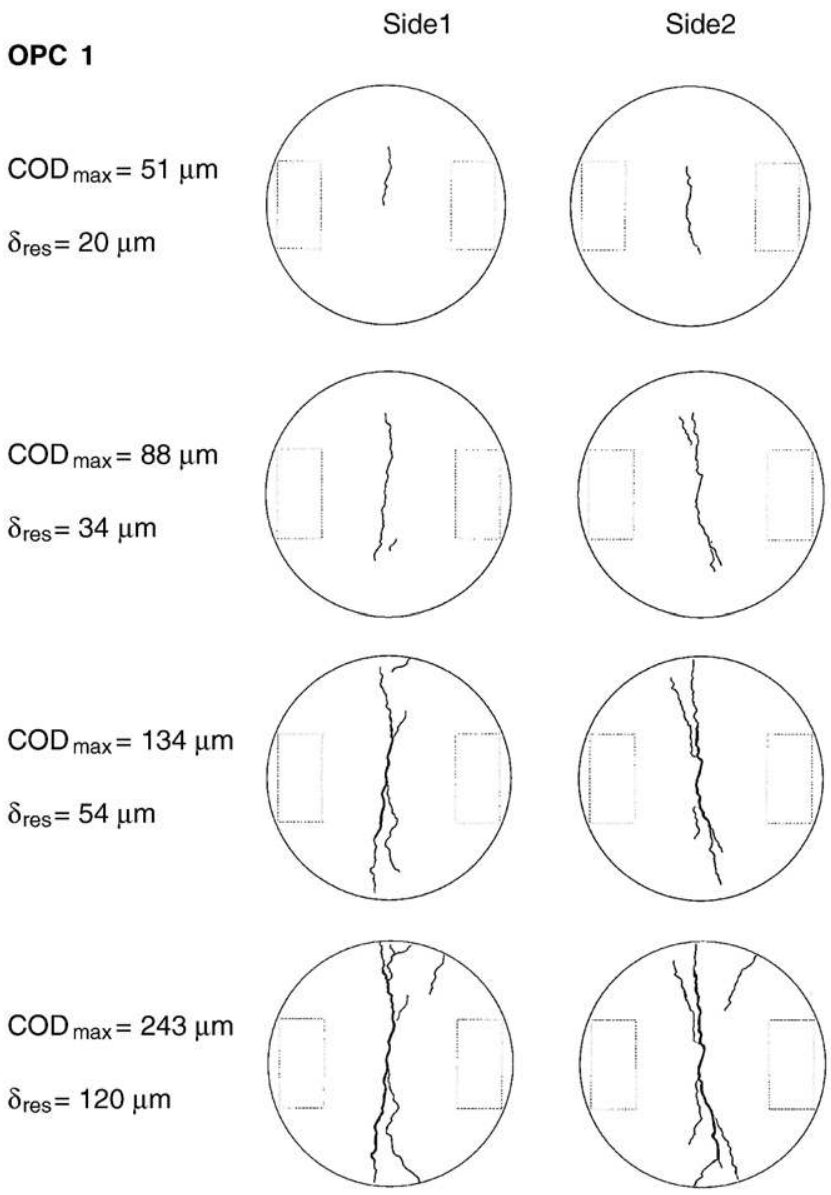

Fig. 10. Crack patterns mapping of OC disc.

\section{HPC 1}

$\mathrm{COD}_{\max }=50 \mu \mathrm{m}$

$\delta_{\text {res }}=20 \mu \mathrm{m}$
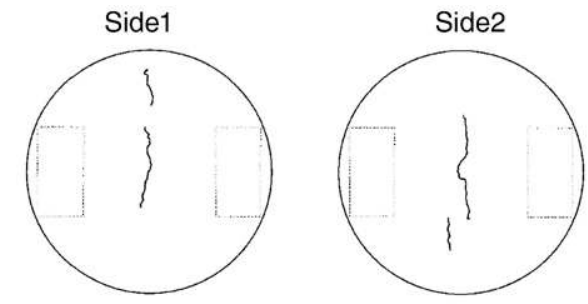

$\mathrm{COD}_{\max }=86 \mu \mathrm{m}$

$\delta_{\text {res }}=40 \mu \mathrm{m}$
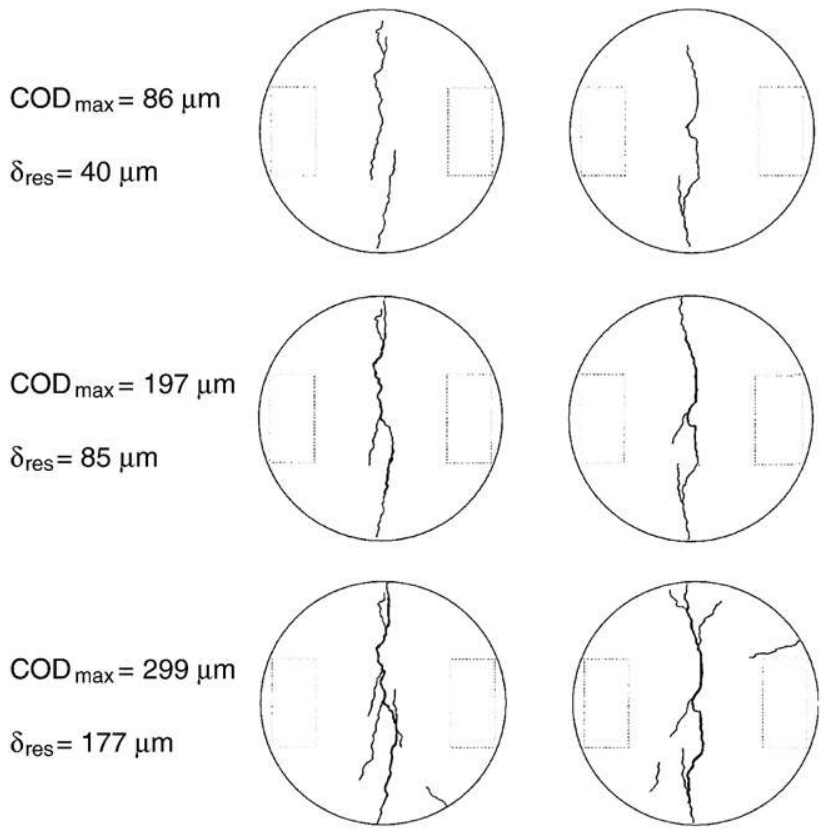

Fig. 11. Crack patterns mapping of HPC disc.

$\beta\left(\mathrm{m}^{-1}\right)$ can be considered as a constant parameter [25]. The conservation of the mass flow through the specimen leads to another relationship (see Eq. (4)) where $k_{\mathrm{A}}$ and $k_{\mathrm{V}}$ are expressed according to the global volumetric outlet gas flow rate $Q$ at atmospheric pressure.

$\frac{1}{k_{\mathrm{A}}}=\frac{1}{k_{\mathrm{V}}}+\left(\beta \frac{M}{R T} \frac{P_{\mathrm{atm}}}{\mu A}\right) Q$

Where $M$ is the molar mass $\left(\mathrm{g} \mathrm{mol}^{-1}\right), R$ is the universal gas constant $\left(\mathrm{J} \mathrm{mol}^{-1} \mathrm{~K}^{-1}\right)$ and $T$ is the temperature $(\mathrm{K})$. The velocity of flows inside the cracks depends on the relative pressure applied to the sample. Then, the determination of $k_{\mathrm{V}}$ consists in measuring $k_{\mathrm{A}}$ for

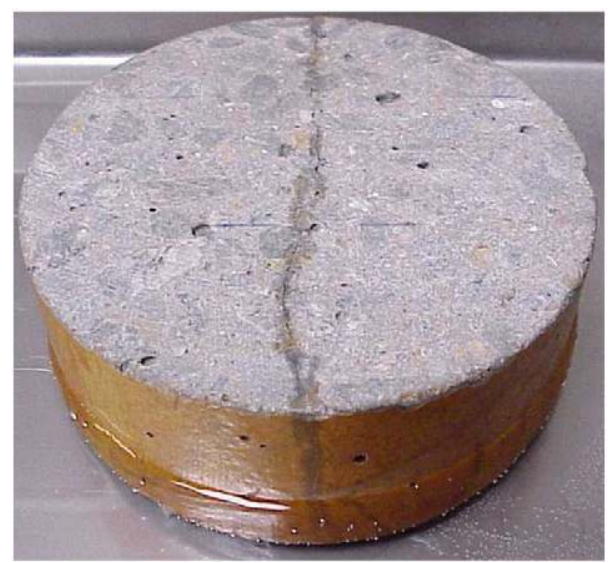

Fig. 12. Wetted zone around the main crack on the upper face of HPC disc during imbibition. 
different pressures $\left(P_{\mathrm{i}}\right)$ and in plotting the inverse of the apparent permeability $\left(1 / k_{\mathrm{A}}\right)$ against the global gas flow $Q$. From the several differential pressures applied, the correlations of the linear regressions are satisfactory and allow the intrinsic permeability coefficients $k_{\mathrm{V}}$ of tested specimens to be determined.

Whatever the considered theory, the apparent permeability decreases when the differential pressure increases. The permeability value is then regarded as the intrinsic gas permeability, $k_{\mathrm{V}}$, determined in Eq. (2) or in Eq. (4) according to the gas flow rate observed. This permeability value depends only on the cracking state and/or on the degree of water saturation of the tested specimen.

\subsection{Water permeability tests}

Water permeability tests are run directly on cracked samples [5] in an air-conditioned room at $\left(20 \pm 1{ }^{\circ} \mathrm{C}\right)$. To avoid any turbulent water flow inside the cracks, the relative inlet pressure ranges between 0.02 and $0.1 \mathrm{MPa}$ and is kept constant throughout one day. The outlet water flow is measured every minute during the first hour and every hour thereafter. From the measures of the mean percolating flow, $Q$, over

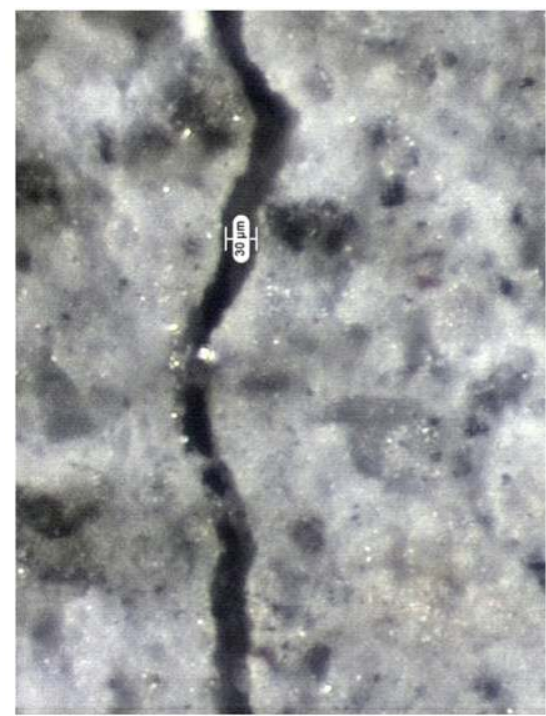

a) $\mathrm{COD}_{\max }=80 \mu \mathrm{m}, \mathrm{w}_{1} \cong 30 \mu \mathrm{m}$

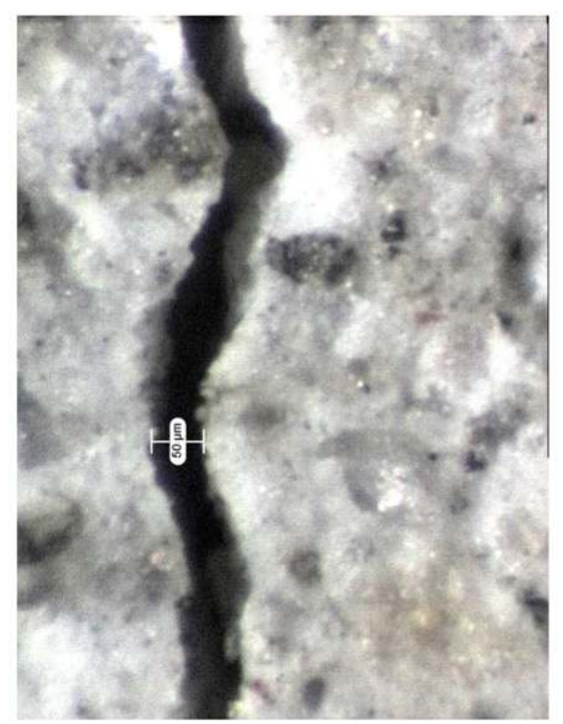

c) $\mathrm{COD}_{\max }=154 \mu \mathrm{m}, \mathrm{w}_{1} \cong 50 \mu \mathrm{m}$
$1 \mathrm{~min}$, the water permeability, $k_{\text {Water }}\left(\mathrm{m}^{2}\right)$ is directly calculated according to Darcy's law:

$k_{\text {Water }}=\mu_{1} \frac{L}{A} \frac{Q}{\Delta P}$

Where $\mu_{1}$ is the dynamic viscosity of water $\left(10^{-3}\right.$ Pa s at $\left.20^{\circ} \mathrm{C}\right), L$ the thickness of the sample, $A$ the cross-sectional area and $\Delta P$ the differential pressure applied.

\section{Results and discussion}

\subsection{COD recovery after unloading}

COD is the main value measurement from two LVDT on both sides of the specimens (Figs. 1 and 2). The residual tensile displacement, $\delta_{\text {res }}$, is recorded $15 \mathrm{~min}$ after complete unloading to take into account the viscous effect, which reduces the COD by a few microns. The relationships between the maximum COD under loading, called $\mathrm{COD}_{\max }$ thereafter, and $\delta_{\text {res }}$ are shown in (Figs. 8 and 9). They are almost linear

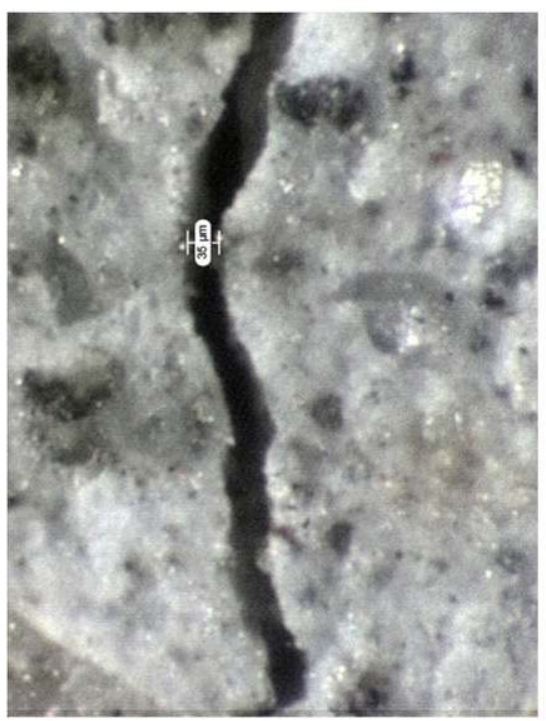

b) $\mathrm{COD}_{\max }=105 \mu \mathrm{m}, \mathrm{w}_{1} \cong 35 \mu \mathrm{m}$

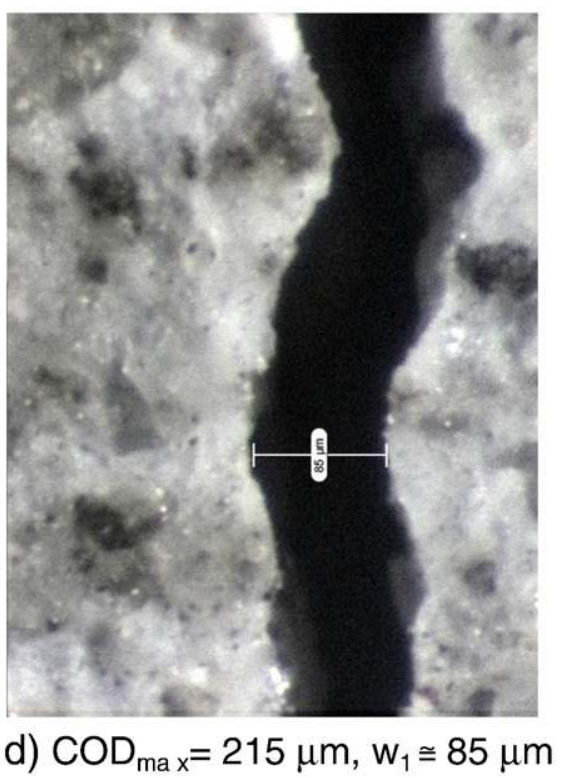

Fig. 13. Sequential observation of the main crack aperture. 


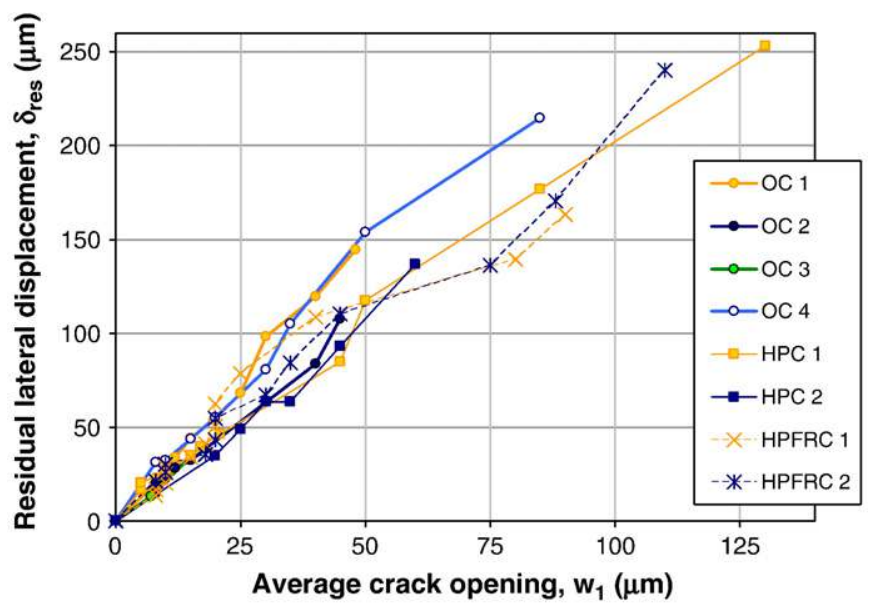

Fig. 14. Width of the main crack, $w_{1}$, versus the residual lateral displacement, $\delta_{\text {res }}$.

until the $\mathrm{COD}_{\max }$ reaches $180 \mu \mathrm{m}$, as observed in other studies [6,15,16]. In that case, the $\mathrm{COD}_{\max }$ to $\delta_{\text {res }}$ ratio is about 2.6 for OC and 2.4 for HPC, but is greater for the fiber-reinforced concrete, about 3.2.

The apertures of the load-induced crack are certainly greater during loading, but thereafter, only the remaining crack opening displacement, called $\delta_{\text {res }}$ is considered, since the permeability tests are not performed under loading. Moreover, the range of $\delta_{\text {res }}$ is wide enough to be correlated to the cracking level of the specimens.

\subsection{Crack patterns}

To investigate the crack characteristics, some specimens were examined using a video microscope with a 200 times magnification. A sequential crack pattern detected on an OC and a HPC concrete disc after a few loading phases is given in Figs. 10 and 11 respectively. It can be noted that, as observed in other studies [15-17,20], the first crack initiates in the center of the specimens (where the uniform tensile stress is developed under the splitting load $[5,6])$, and the crack grows toward the edge of the specimen as the COD increases. With further loading, additional fine cracks appear but the width of the main crack, called $w_{1}$, still grows, and remains for the most part greater than the newly created cracks. The main crack of the discs after the last loading phase can be easily highlighted after $1 \mathrm{~h}$ of water imbibition: Fig. 12 shows the wetted zone around the main crack observed on the upper side of on OC disc.

The specimens should not break apart during the splitting test. Under loading, beyond a COD of $500 \mu \mathrm{m}$, further branch cracks connected to the main one are observed and specimens become too fragile to be handled for a permeability test.

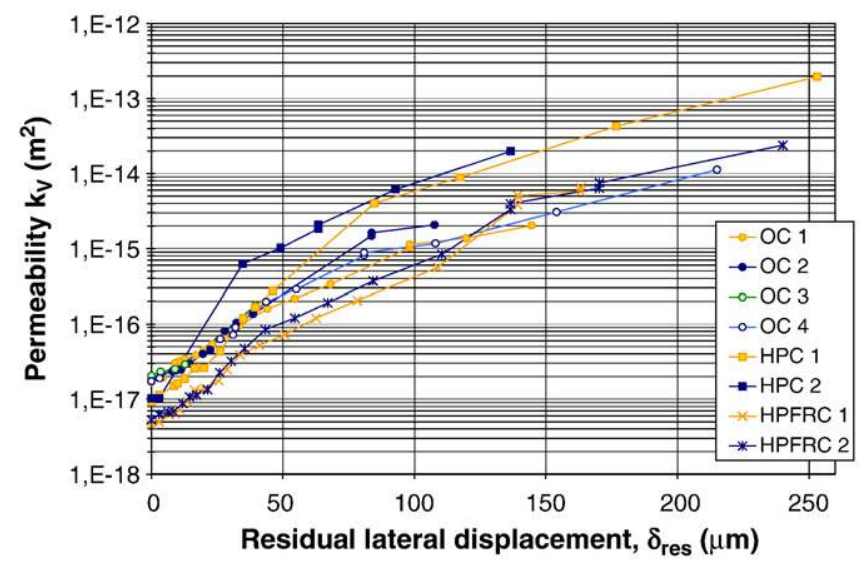

Fig. 15. Gas permeability versus the residual lateral displacement, $\delta_{\text {res }}$.

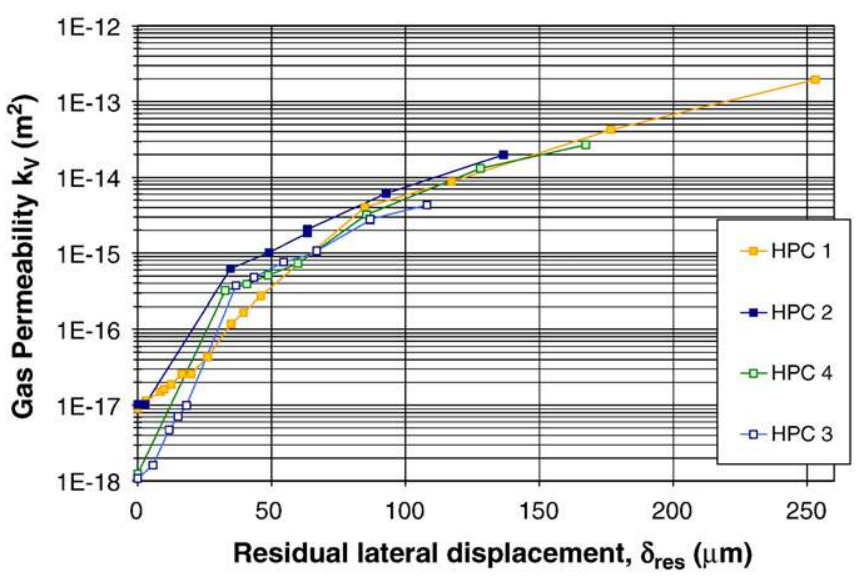

Fig. 16. Gas permeability of a HPC disc at different water saturation degrees versus the residual lateral displacement, $\delta_{\text {res. }}$.

\subsection{Width of the main crack, $w_{1}$}

Generally, beyond a $30 \mu \mathrm{m} \mathrm{COD}_{\max }$, a crack is observed on both sides of the discs and initiates the formation of the main crack. The average opening of this crack after unloading, $w_{1}$, is about $3 \mu \mathrm{m}$ and its length is about $30 \mathrm{~mm}$ (Fig. 10). $w_{1}$ is measured after each loading phase with an accuracy of a few microns using a video microscope. A sequential aperture observation of the same spot, located close to the center of the specimen, is shown as an example in Fig. 13.

The relationship between the $\mathrm{COD}_{\max }$ and $w_{1}$, shown in Fig. 14, is almost linear and the same for each concrete specimen: $w_{1} / \mathrm{COD} \cong 0.5$.

\subsection{Global increase in the permeability of specimens}

After unloading, the applied splitting tests can increase the initial permeability $k_{\mathrm{V}}$ of uncracked concrete specimens by about four orders of magnitude. Fig. 15 shows the evolution of the permeability of each tested disc according to $\delta_{\text {res }}$.

The gas permeability markedly increases starting from a certain threshold of residual displacement, $\delta_{\text {res }}$, around $15 \mu \mathrm{m}$. This threshold corresponds to a lateral displacement under loading, $\mathrm{COD}_{\max }$, of about $25 \mu \mathrm{m}$. When water is used as percolating fluid, this threshold has been observed beyond $50 \mu \mathrm{m}$ of $\mathrm{COD}_{\max }$ [15-17]. When comparing these results to various published data $[4,5]$, it is assumed that gas permeability is more sensitive than water permeability of concrete to load-induced damage [20]. Beyond this threshold, the crack pattern should control the global gas flow through the disc [2].

Two different drying procedures were applied to the HPC disc, leading to different water saturation degrees: $3 \%$ for HPC 1 and 2, and 35\% for HPC 3 and 4 (Table 3 ). The gas permeability of the uncracked specimen

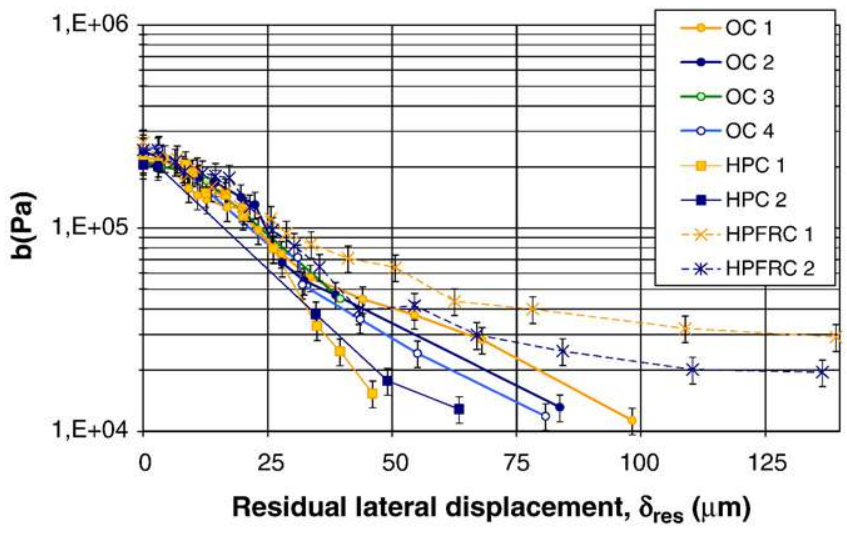

Fig. 17. Klinkenberg coefficient, $b$, versus the residual lateral displacement, $\delta_{\text {res. }}$ 


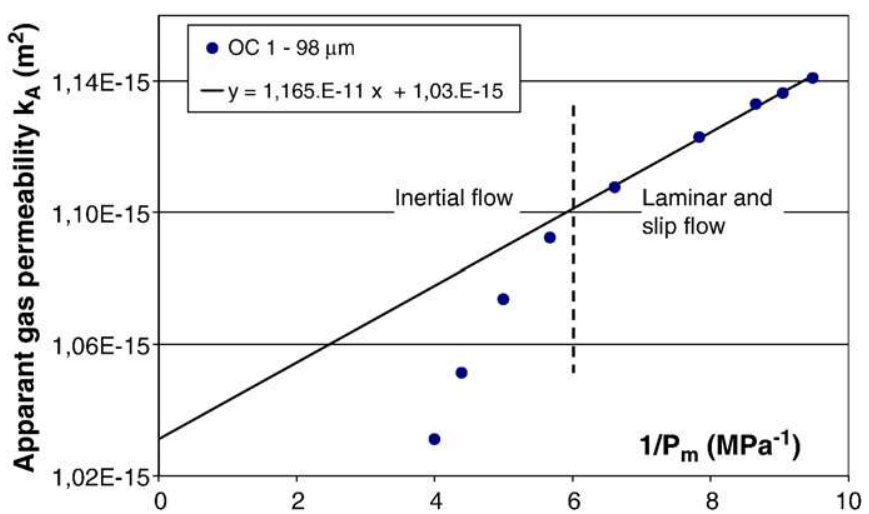

Fig. 18. Determination of the intrinsic gas permeability, $k_{\mathrm{V}}$, from the measurement of $k_{\mathrm{A}}$ for different inlet gas pressure: According to the Klinkenberg's law and considering the lower inlet gas pressures.

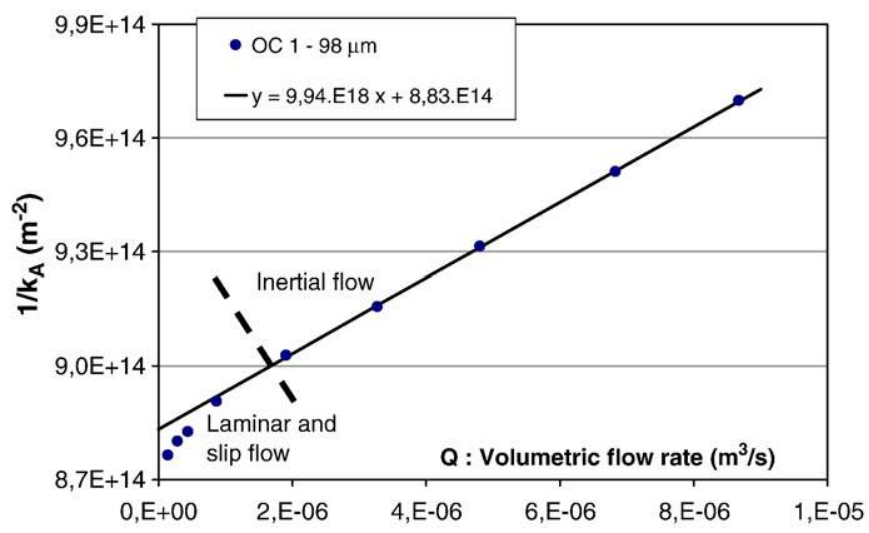

Fig. 19. Determination of the intrinsic gas permeability, $k_{\mathrm{V}}$, from the measurement of $k_{\mathrm{A}}$ for different inlet gas pressure: According to the Dupuit-Forcheimer's law and considering the higher inlet gas pressures.

depends on the saturation degree but, as shown in Fig. 16, if the crack pattern is created (i.e. $\delta_{\text {res }}>15 \mu \mathrm{m}$ ), the water saturation degree of specimens no longer affects the global gas permeability measurement. As observed in a previous study, in damaged specimens, the cracks convey the larger part of the gas flow, with no influence of the saturation degree [2]. This point is also discussed in Section 3.8.

\subsection{Laminar-turbulent gas flow transition}

In uncracked or less cracked specimens, the Klinkenberg method is used to calculate the intrinsic gas permeability (see Section 2.4). When the residual displacement, $\delta_{\text {res }}$, increases, the mean size of the gas flow path increases and the coefficient $b$, see Eq. (2) accounting for slip flow contribution, decreases (Fig. 17). The values of $b$ are close for each undamaged specimen but a difference is observed beyond $30 \mu \mathrm{m}$ COD. The decrease of $b$ is more pronounced in HPC, letting us suppose that, for a given COD, the mean hydraulic diameter conveying the gas flow is greater in cracked HPC than OC, whereas steel fibers significantly limit the increase of the hydraulic diameter of the loadinduced cracks inside HPFRC (High-Performance Fiber Reinforced Concrete).

If some turbulent flows occur, the correlation of $k_{\mathrm{A}}$ compared to the inverse of the mean gas pressure is not satisfactory, and could lead to a negative value of $b$. In such a case, the Klinkenberg method can no longer be applied. In the test configuration, when the permeability ranges between $8 \times 10^{-16}$ and $8 \times 10^{-15} \mathrm{~m}^{2}$ and the inlet gas pressure is superior to $0.1 \mathrm{MPa}$, a laminar-turbulent gas flow transition always occurs. Then, seven to eight measurements are made to determine the intrinsic permeability according to either Eq. (2), considering the lower inlet pressure, or according to Eq. (4), considering the greater inlet pressure. In that case, a pair of data is plotted on the graph in Fig. 15 for the same $\delta_{\text {res. }}$ It corresponds to the transition between the two considered methods. A good match can be observed, especially for HPC.

When the gas flow transition occurs for an inlet gas pressure close to $0.1 \mathrm{MPa}$, the permeameter range of inlet pressure allows for a precise observation, on the one hand, of laminar and slip flows, and on the other hand, of turbulent or inertial flows. In the first case, the determination of the intrinsic gas permeability consists in measuring $k_{\mathrm{A}}$ from the lower inlet pressures and in plotting it against the inverse of the mean pressure $\left(1 / P_{\mathrm{m}}\right)$, ( see the graph $k_{\mathrm{A}}$ versus $1 / P_{\mathrm{m}}$, Fig. 18). In the second case, it consists in measuring $k_{\mathrm{A}}$ from the greater inlet pressures and in plotting the inverse of $k_{\mathrm{A}}$ against the global gas flow $Q$ (see the graph $1 / k_{\mathrm{A}}$ versus $Q$. Fig. 19).

The graphs shown in Figs. 18 and 19 report the experimental data obtained during a gas permeability test procedure for an OC cracked specimen with a $98 \mu \mathrm{m}$ of residual displacement, $\delta_{\text {res }}$. It should be noted that experimental data show a coherent transition between Klinkenberg's and Dupuit-Forcheimer's laws. The intrinsic permeability values determined according to each method (Section 2.4) lead to a difference lower than $10 \%$.

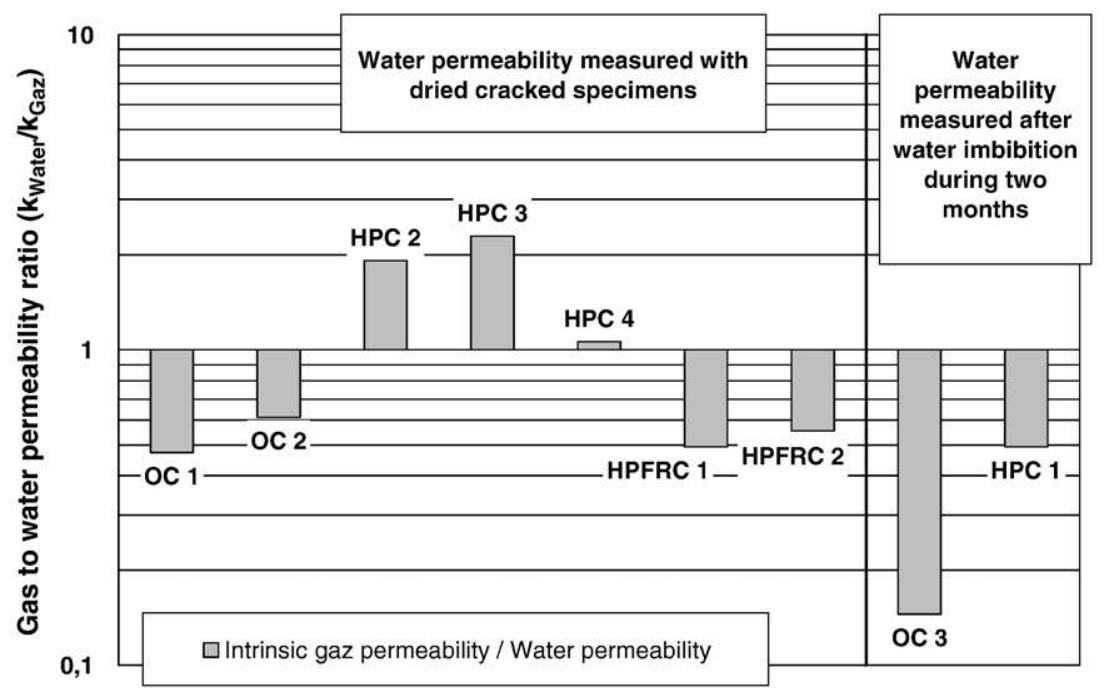

Fig. 20. Comparison between gas and water permeability of cracked specimens. 


\subsection{Water permeability tests}

After the last loading phase and after a final gas permeability test, a water permeability test is performed. Due to the water-cement matrix interaction, (i.e. dissolution/precipitation of calcite inside the cracks due to leaching and exposure of previously unhydrated components [7-9]), the water flow through the cracks is gradually reduced with time as observed in other studies [11,12]. In order to limit the self-sealing effect on measurements, the water permeability, $k_{\text {Water }}$, is calculated from the water flow percolating during the first minute only.

During the previously performed gas permeability test, it was noted that the laminar to turbulent flow transition in cracks (see Section 2.4) occurs when the Reynolds number ranges between 3 and 5 for a gas flow in the same cracked specimens [5]. The limited water pressure gradient applied (see Section 2.5) insures keeping a Reynolds number lower than 3 and minimizing the self-sealing effect [9]. No turbulent flow should occur during the water permeability test, and water permeability is calculated according to Darcy's law (Eq. (5)).

The comparisons between $k_{\text {Water }}$ and the intrinsic gas permeability, $k_{\mathrm{Gaz}}$, with $k_{\mathrm{Gaz}}=k_{\mathrm{V}}$ calculated from Eqs. (2) or (4) according to the flow regime, and $k_{\text {Water }}$, are shown in Fig. 20 for discs of different concrete types. The two values are very similar and the ratios $k_{\mathrm{Water}} / k_{\mathrm{Gaz}}$ ranges between 0.47 and 2.3 .

Some specimens are first water imbibed for two months so that they are water saturated before the test is carried out (see Fig. 12). In that case, as shown in Fig. 20, the first percolating flow indicates that water permeability is four times lower, and the water flow still decreases during the test. Then, the global permeability of cracked concrete tends to decrease with both percolating flow and the amount of time the cracks are exposed to water [5,9].

\subsection{Relationships between $C O D$ and relative increase in permeability}

The model proposed to analyze the increase in permeability of a cracked specimen derived from the Hagen-Poiseuille theory for viscous flow between rough parallel-plate. The matrix is then assumed to be impermeable and the percolation occurs only through the cracks as a viscous flow. The global permeability $k_{v}^{\prime}$ of this hypothetic media can be written as following:

$k_{V}^{\prime}=\frac{\xi}{\Delta} \frac{w^{3}}{12}$

Where $\xi$ is the reduction factor comprising the tortuosity or roughness of cracks, $w$ is the crack width $(\mathrm{m})$ and $\Delta$ is the mean distance between cracks $(\mathrm{m})$. The reverse $(1 / \Delta)$ corresponds to the crack density $\left(\mathrm{m} / \mathrm{m}^{2}\right)$ which is considered to estimate $\Delta$.

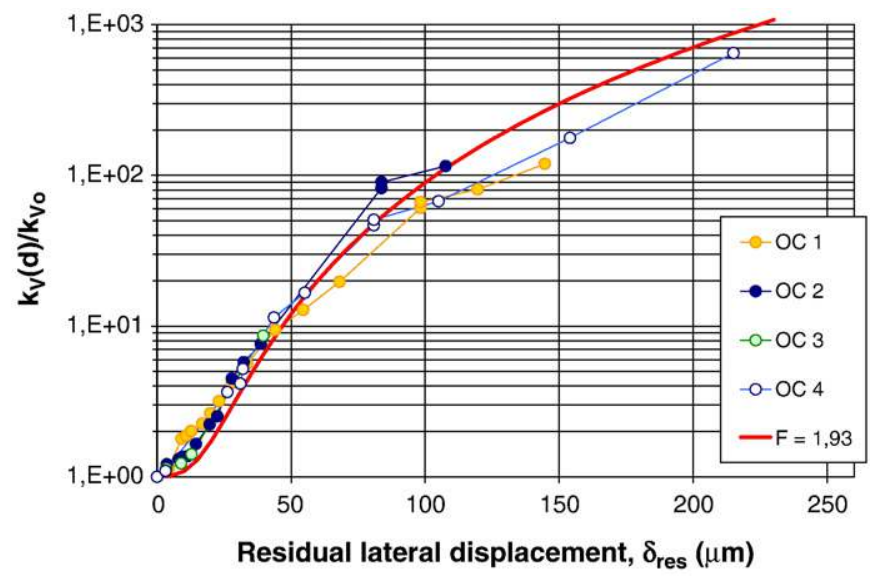

Fig. 21. Adjustment of the model to the relative increases in permeability measured for OC discs versus the residual lateral displacement, $\delta_{\text {res }}$.

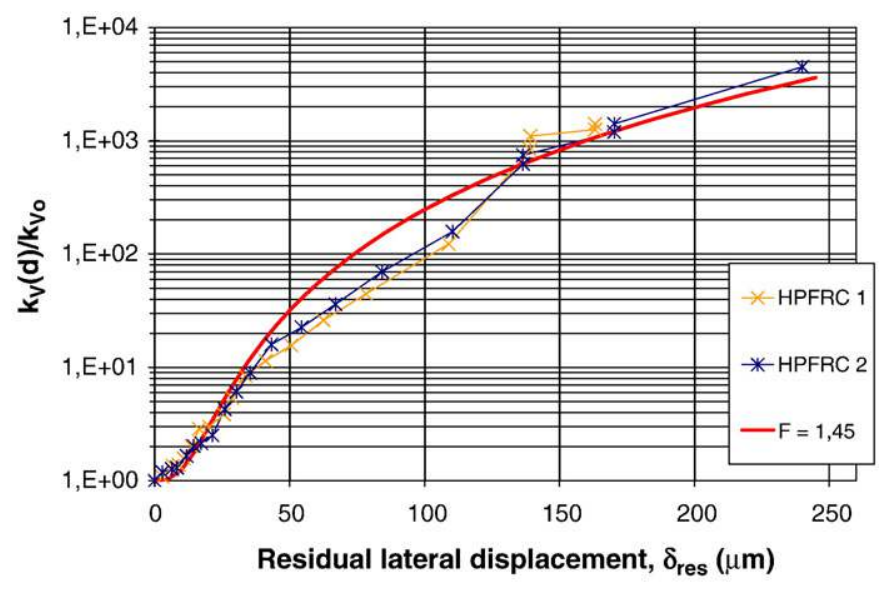

Fig. 22. Adjustment of the model to the relative increases in permeability measured for HPFRC discs versus the residual lateral displacement, $\delta_{\text {res }}$.

The lateral displacement or COD corresponds to an extension of the concrete. The yield tensile strain of concrete is negligible and the recorded CODs can be regarded as the sum of the width of all existing cracks in the discs due to diametrical load. In fact, it could be assumed that there is a single main crack crossing the discs (Section 3.3). The flow inside the cracks varies in proportion to the width cubed. The few other fine cracks would only contribute to a limited flow of the total gas flow through the sample. Nevertheless, the sum of the width of these other cracks must be taken into account in terms of displacement. A correcting factor $\gamma$ is introduced to estimate the main crack width, $w_{1}$, from the measured residual displacement, $\delta_{\text {res }}$. From the main crack widths measured using the video microscope and the recorded data of $\delta_{\text {res }}, \gamma$ can be adjusted to a value equal to 0.5 for all concrete type discs (see Section 3.3, Fig. 14).

The global permeability of a damaged disc, $k_{\mathrm{V}}(\mathrm{d})$ can be considered as the sum of its initial permeability, $k_{\mathrm{V}}$, and of the permeability of the loadinduced cracks in an impermeable media, $k_{\mathrm{V}}^{\prime}$ [2], i.e. $k_{\mathrm{V}}(\mathrm{d})=k_{\mathrm{V}} \mathrm{O}+k_{\mathrm{V}}^{\prime}$. According to this model and Eq. (6), the relative increase in permeability (i.e. the ratio $k_{\mathrm{V}}(\mathrm{d}) / k_{\mathrm{V} O}$ ) versus the displacement $\delta_{\text {res }}$, is given in the following equation:

$\frac{k_{\mathrm{V}}(\mathrm{d})}{k_{\mathrm{V}} \mathrm{O}}=1+\frac{\xi}{k_{\mathrm{V}} \mathrm{0} \Delta} \frac{\left(\gamma \delta_{\mathrm{res}}\right)^{3}}{12}$

A polynomial fitting is then carried out by assuming the relationship given in Eq. (7). The developed length of the main crack, approximately equal to $0.1 \mathrm{~m}$, and the section area of the disc, equal to $0.01 \mathrm{~m}^{2}$, lead to

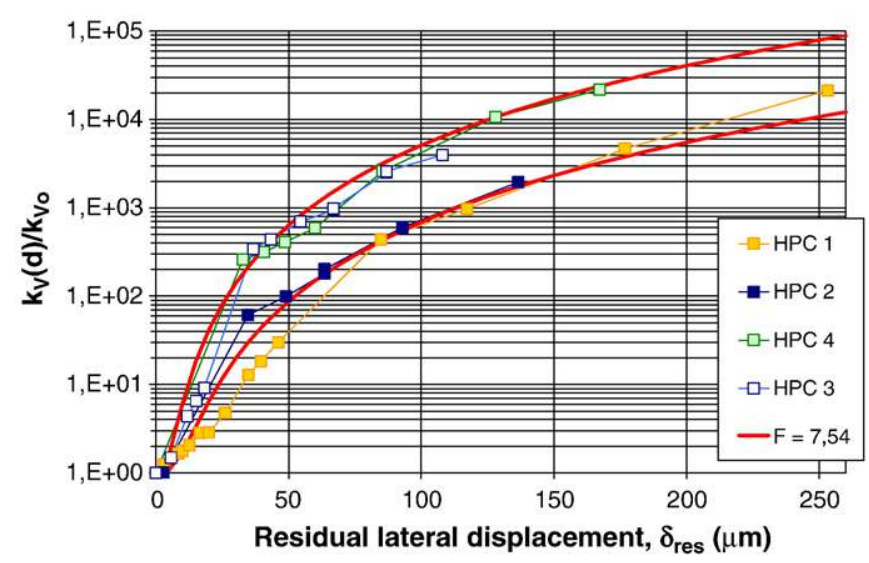

Fig. 23. Adjustment of the model to the relative increases in permeability measured for HPC discs versus the residual lateral displacement, $\delta_{\text {res. }}$. 
Table 4

Fitted parameter, $F$, and determinations of the reducing factor, $\xi$.

\begin{tabular}{llll}
\hline & OC & HPC & HPFRC \\
\hline$F=\xi \gamma^{3}$ & $1.93 \times 10^{-3}$ & $7.54 \times 10^{-3}$ & $1.46 \times 10^{-3}$ \\
$\xi$ value if $\gamma=0.5$ & 0.015 & 0.060 & 0.012 \\
$\begin{array}{l}\xi \text { value determined from the main } \\
\text { crack width } w_{1} \text { measurement }\end{array}$ & 0.03 & 0.1 & 0.01 \\
\hline
\end{tabular}

$\Delta \cong 0.1 \mathrm{~m}$. The fitted parameter is $F$, with $F=\xi \gamma^{3}$. The adjustment between the relative increase in permeability measured for OC, HPFRC and HPC discs and the model is given in Figs. 21-23 respectively.

It should be noted that the relative increases in the permeability of discs, for the same concrete type and for a given water content, are similar. In HPFRC, above a $\mathrm{COD}_{\max }$ of $330 \mu \mathrm{m}$ (i.e. $\delta_{\text {res }}$ greater than $130 \mu \mathrm{m})$, the steel fiber stitching of the main crack comes loose or apart, thus drastically reducing crack recovery (Fig. 9), and inducing a sudden drop in the recovery evolution of Fig. 22.

The theoretical curves fit well. The numerical values of $F$, determined by fitting, for each concrete tested, are reported in Table 4 . The values of the correcting factor $\xi$ can be evaluated from the adjusted value of $\gamma$ (2nd line in Table 4 ) or from the average width measurements of the main crack, $w_{1}$, (Section 3.3) using the relationship given in Eq. (6), (3rd line in Table 4).

The value of $\xi$ cannot be accurately determined but the results show that it is significantly higher in HPC, and lets one suppose that the roughness of cracks is lower inside HPC. The steel fibers should increase roughness and crack branching in HPFRC, no matter the COD, [11,17], so the global roughness of the tensile cracks occurring in HPFRC is higher than in HPC without fibers, and is also lower than the roughness of cracks occurring in $\mathrm{OC}$.

\subsection{Effect of water saturation degree of cracked concrete on gas permeability}

As discussed in (Section 3.4), two different drying procedures were applied to the HPC disc, leading to different water saturation degrees: $3 \%$ for HPC $1-2$, and $35 \%$ for HPC 3-4 (Table 3). This difference induces one order of magnitude spread in the initial gas permeability $k_{\mathrm{V}} \mathrm{O}$, close to $10^{-17} \mathrm{~m}^{2}$ for HPC $1-2$ and to $10^{-18} \mathrm{~m}^{2}$ for HPC 3-4 (see Fig. 15). In both cases, the fitting of the experimental data according to the law defined in Eq. (7) as a function of the two initial values of permeability, $k_{\mathrm{V}}$, leads to the same parameter $F$, Fig. 23. Therefore, only one value of $F$ can simulate many relative evolutions of gas permeability inside a given concrete type according to $\delta_{\text {res }}$ even if the referential gas permeability, $k_{\mathrm{v}}$, decreases due to a higher water saturation degree. This confirms that the water saturation degree, in the studied range, has no influence on the parameters $\gamma$ and $\xi$ and consequently on the relative increase in gas permeability of the cracked concrete.

\section{Conclusions}

The specimens were sequentially loaded and tested in the gas permeameter after each unloading for 4 to 11 cycles. The observations of the crack pattern after each load cycle show that in most cases, a single main crack located on the load axis occurred. After its appearance, the main crack aperture observations show that it increases almost proportionally to the measured COD.

The gas permeability testing of cracked specimens requires several measures of apparent permeability, (i.e. different inlet gas pressures). The analysis of experimental data shows a coherent transition between Klinkenberg's and Dupuit-Forcheimer's laws, making it possible to determine the intrinsic permeability of cracked specimens (or permeable specimens) using gas.

The water flow percolating through most cracked specimens gradually reduces with time, due to water-cement matrix interaction. If only the flow produced during the first part of the water permeability test is considered, then water and gas permeability measurements tend towards the same value. This result confirms that permeability should be considered as an intrinsic parameter to evaluate the global effect of loadinduced cracks on concrete durability or performance.

Results suggest that permeability increases proportionally to the cube of the COD, as shown theoretically for viscous flow in rough fractures. A parameter $\gamma$ taking into account the tensile crack density and the crack-width distribution, should be introduced to estimate the roughness of the surface $\xi$.

In damaged specimens, the cracks convey the larger part of flow, with no influence from the saturation degree. The presented law can be applied to many types of cracked concrete, with or without fiber reinforcement, and extended to various water saturation degrees.

In spite of the difficulty in achieving a precise experimental determination of $\xi$, the results show that the correction factor depends on the concrete mixes. In HPC, load-induced cracks should be smoother than the tensile cracks in OC, as well as in HPFRC.

The roughness of a crack may increase the contact surface between water and cement matrix and, as a consequence, accelerate the selfsealing kinetic. Even if the water-to-cement ratio is lower in HPC, the higher content of potentially unhydrated components does not balance the effect of a lower tortuosity since the ratio of water-to-gas permeability, $k_{\text {Water }} / k_{\mathrm{Gaz}}$, is higher in HPC than in OC.

Reinforcing fibers should increase the tortuosity and the roughness of the cracks. Fiber-reinforced concrete appears to be a more effective structural material than plain concrete, in terms of permeability and durability as well as mechanical properties.

\section{References}

[1] M. Choinska, A. Khelidj, G. Chatzigeorgiou, G. Pijaudier-Cabot, Effects and interactions of temperature and stress-level related damage on permeability of concrete, Cement and Concrete Research 37 (2007) 79-88.

[2] V. Picandet, A. Khelidj, G. Bastian, Effect of axial compressive damage on gas permeability of ordinary and high performance concrete, Cement and Concrete Research 31 (2001) 1525-1532.

[3] H. Meziani, F. Skoczylas, An experimental study of the mechanical behaviour of a mortar and of its permeability under deviatoric loading, Materials and Structures 32 (1999) 403-409.

[4] G. Chatzigeorgiou, V. Picandet, A. Khelidj, G. Pijaudier-Cabot, Coupling between progressive damage and permeability of concrete: analysis with a discrete model, International Journal for Numerical and Analytical Methods in Geomechanics 29 (2005) 1005-1018.

[5] V. Picandet, Influence d'un endommagement mécanique sur la perméabilité et sur la diffusivité hydrique des bétons, thèse de doctorat ( $\mathrm{PhD}$ thesis in french), Université de Nantes, France, (2001), available online: http://www.ec-nantes.fr.

[6] M. Choinska, Effets de la température, du chargement mécanique et de leurs interactions sur la perméabilité du béton de structure, thèse de doctorat $(\mathrm{PhD}$ thesis in french), Université de Nantes, France, (2006).

[7] N. Hearn, C.T. Morley, Self-sealing property of concrete - experimental evidence, Materials and Structures 30 (1997) 404-411.

[8] N. Hearn, Self-sealing, autogeneous healing and continued hydration: what is the difference? Materials and Structures 31 (1998) 563-567.

[9] C. Edvardsen, Water permeability and autogeneous healing of cracks in concrete, ACI Materials Journal 96 (4) (1999) 448-454.

[10] H. Loosveldt, Z. Lafhaj, F. Skoczylas, Experimental study of gas and liquid permeability of a mortar, Cement and Concrete Research 32 (2002) 1357-1363.

[11] J-P. Charron, E. Denarié, E. Brühwiler, Transport properties of water and glycol in an ultra high performance fiber reinforced concrete (UHPFRC) under high tensile deformation, Cement and Concrete Research 38 (2008) 689-698.

[12] H-W. Reinhardt, M. Jooss, Permeability and self-healing of cracked concrete as a function of temperature and crack width, Cement and Concrete Research 33 (2003) 981-985.

[13] S. Granger, A. Loukili, G. Pijaudier-Cabot, G. Chanvillard, Experimental characterization of the self-healing of cracks in an ultra high performance cementitious material: mechanical tests and acoustic emission analysis, Cement and Concrete Research 37 (2007) 519-527.

[14] J.J. Kollek, The determination of the permeability of concrete to oxygen by the Cembureau method - a recommendation, Materials and Structures 22 (1989) 225-230.

[15] K. Wang, C. Jansen, S.P. Shah, A.F. Karr, Permeability study of cracked concrete Cement and Concrete Research 27 (1997) 381-393 (n³).

[16] C.M. Aldea, S.P. Shah, A. Karr, Permeability of cracked concrete, Materials and Structures 32 (1999) 370-376.

[17] S.P. Shah, J.S. Lawler, J. Rapoport, Reinforcing fibers and the permeability of cracked concrete with implications for durability, 3rd international conference on concrete under sever conditions: Environment and loading, Keynote paper, Vancouver, Canada, vol. 1, 2001, pp. 38-49. 
[18] A. Djerbi, S. Bonnet, A. Khelidj, V. Baroghel-bouny, Influence of traversing crack on chloride diffusion into concrete, Cement and Concrete Research 38 (2008) 877-883.

[19] C.A. Davy, F. Skoczylas, J.-D. Barnichon, P. Lebon, Permeability of macro-cracked argillite under confinement: gas and water testing, Physics and Chemistry of the Earth 32 (2007) 667-680.

[20] V. Picandet, A. Khelidj, Gas and water permeability of cracked concrete, Internationa Conference on Performance of Construction Materials, Le Caire, Egypt, vol. 2, 2003 , pp. 1433-1442.

[21] L. Daniel, A. Loukili, Behavior of high-strength fiber-reinforced concrete beams under cyclic loading, ACI Structural Journal 99 (2002) 248-256.
[22] F. Jacobs, Permeability to gas of partially saturated concrete, Magazine of Concrete Research 50 (2) (1998) 115-121.

[23] A. Abbas, M. Carcasses, J-P. Ollivier, Gas permeability of concrete in relation to its degree of saturation, Materials and Structures 32 (1999) 3-8.

[24] L.J. Klinkenberg, The permeability of porous media to liquid and gases, American Petroleum Institute, Drilling and Production Practice 200-213 (1941).

[25] P.C. Carman, Flow of Gases Through Porous Media, Academic press, New York, 1956.

[26] F.A.L. Dullien, Porous Media, Fluid Transport and Pore Structure, Academic press, London, 1979. 